Marcin KRATOFIL ${ }^{1}$

Robert ZARZYCKI ${ }^{2}$

Rafał KOBYŁECKI ${ }^{3}$

Zbigniew BIS ${ }^{4}$

\title{
ANALIZA PROCESU TORYFIKACJI BIOMASY
}

\begin{abstract}
W artykule dokonano zestawienia oraz analizy zmian parametrów fizykochemicznych biomasy w efekcie poddania jej obróbce termicznej w temperaturze $350^{\circ} \mathrm{C}$. Wyniki badań wskazują, że umożliwia to właściwie całkowite usunięcie wilgoci z toryfikowanej biomasy, a dodatkowo jest widoczny wyraźny spadek zawartości części lotnych w produkcie, przy jednoczesnym wzroście zawartości tzw. fixed carbonu. Wykazano także, że toryfikacja biomasy powoduje wzrost zawartości węgla w produkcie, a także wzrost parametrów energetycznych (ciepło spalania i wartość opałowa).
\end{abstract}

Słowa kluczowe: biomasa, obróbka termiczna, toryfikacja

\section{Wstęp}

Według norm Unii Europejskiej biomasa obejmuje materiał pochodzenia biologicznego ulegający biodegradacji, który jest wytwarzany na plantacjach lub jest materiałem odpadowym powstającym w leśnictwie, rolnictwie itp. [1, 3, 6].

Wyróżnia się następujące formy biomasy:

- roślinna - gromadzona głównie podczas produkcji i przetwarzania produktów roślinnych (odpady drzewne, słoma odpadowa) lub jako materiał hodowany w celach energetycznych (plantacja wierzby i topoli) - są to tzw. energetyczne surowce pierwotne,

- zwierzęca - pochodząca z fermentacji osadów w oczyszczalni ścieków lub z fermentacji odpadów organicznych na składowiskach śmieci,

- gazowa - jako tzw. gaz pirolityczny,

- ciekła - biodiesel, bioetanol, metanol.

Biomasa drzewna charakteryzuje się niższą wartością opałową i zawartością siarki w porównaniu $\mathrm{z}$ węglem, a powstały z jej spalania $\mathrm{CO}_{2}$ nie zwiększa

\footnotetext{
1 Autor do korespondencji/corresponding author: Marcin Kratofil, Katedra Inżynierii Energii, Politechnika Częstochowska, ul. Brzeźnicka 60a, 42-200 Częstochowa, tel.: (34) 3257334, wew. 18, e-mail: mkratofil@is.pcz.czest.pl.

${ }^{2}$ Robert Zarzycki, Politechnika Częstochowska, zarzycki@is.pcz.czest.pl.

${ }^{3}$ Rafał Kobyłecki, Politechnika Częstochowska, rafalk@is.pcz.czest.pl.

${ }^{4}$ Zbigniew Bis, Politechnika Częstochowska, zbis@is.pcz.czest.pl.
} 
efektu cieplarnianego [3]. Wartość opałowa to jeden z podstawowych parametrów fizykochemicznych biopaliw stałych. Waha się od 6-8 MJ/kg dla biomasy wilgotnej (50-60\%), do $15-17 \mathrm{MJ} / \mathrm{kg}$ dla biomasy podsuszonej (10-20\%) i aż do $19 \mathrm{MJ} / \mathrm{kg}$ dla biomasy całkowicie wysuszonej. Wartość opałowa zależy od wilgotności biomasy i zmniejsza się wraz z jej wzrostem (rys. 1.).

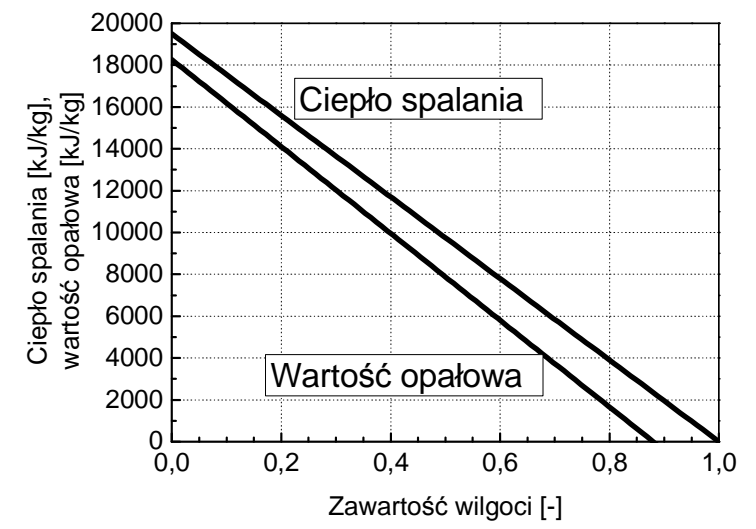

Rys. 1. Zależność ciepła spalania oraz wartości opałowej górnej i dolnej wybranej biomasy (zrębki drzewne) od zawartości wilgoci

Fig. 1. The effect of fuel moisture on both high-heat and lower heating value and heat of combustion for selected biomass (wood chips)

Gwałtowny spadek wartości opałowej wraz ze wzrostem wilgotności wynika głównie z malejącej zawartości suchej masy w masie całkowitej, a częściowo ze strat energii potrzebnej do odparowania większych ilości wilgoci $[2,7]$. Im bardziej paliwo jest suche, tym mniej energii potrzeba do odparowania wody, co oznacza, że proces jest korzystniejszy energetycznie. Z tego względu niektóre rodzaje biomasy powinny być dosuszone, aby uzyskać pożądane parametry spalania oraz określoną wartość energetyczną paliwa [4, 8]. Kolejnym powodem podsuszania biomasy są względy jej transportu i przechowywania. Transport wilgotnej biomasy jest bardziej kosztowny w porównaniu z transportem biomasy poddanej procesowi obróbki termicznej. Dodatkowo składowanie i przechowywanie wilgotnej biomasy jest także utrudnione ze względu na zachodzące w niej procesy biologiczne, takie jak procesy gnilne. Mając na uwadze wspomniane względy energetyczne i ekonomiczne, w przypadku wykorzystywania biomasy konieczna wydaje się jej waloryzacja przez obróbkę termiczną.

Jednym ze sposobów waloryzacji biomasy jest jej toryfikacja. W energetyce toryfikacja to proces przetwarzania biomasy typu lignino-celulozowego w paliwo stałe o właściwościach zbliżonych do węgla. Polega na termicznej obróbce biomasy w zakresie temperatur $200-400^{\circ} \mathrm{C}$ pod ciśnieniem zbliżonym do atmosferycznego, bez dostępu tlenu. W wyniku działania temperatury w zakresie $240-280^{\circ} \mathrm{C}$ następuje rozerwanie długich, silnych łańcuchów ligniny i celulozy, dzięki czemu uzyskuje się stosunkowo kruchy produkt.

Zmiany właściwości biomasy typu lignino-celulozowego w procesie toryfikacji następują w wyniku modyfikacji struktury jej głównych składników: ligniny, hemicelulozy i w mniejszym stopniu celulozy. Proces powinien być tak pro- 
wadzony, żeby uzyskać pożądane właściwości mechaniczne (np. wymaganą przemiałowość) przy minimalnej stracie energetycznej, spowodowanej głównie utratą części lotnych. Etapami tego procesu są: suszenie, piroliza i zgazowanie, odbywające się w reaktorze o kontrolowanej temperaturze. Ze względu na sposób doprowadzenia ciepła do reaktora dzieli się je na dwa typy: reaktory pośrednie, w których ciepło jest dostarczane do biomasy przeponowo przez nośnik energii, np. parę wodną, wodę, olej, spaliny, oraz reaktory bezpośrednie, w których ciepło jest przekazywane bezpośrednio do biomasy od spalin lub innego gazu reaktorowego (np. zgazowywarki i suszarnie fluidalne).

Ze względu na bezpośredni kontakt gorącego czynnika z surowcem drugi typ reaktorów umożliwia krótszy czas przebywania, jednak takie rozwiązanie jest trudniejsze w zastosowaniu. Najnowsze koncepcje reaktorów zakładają konstrukcje na wzór pieca obrotowego bądź reaktora ślimakowego z wykorzystaniem torgazu jako źródła ciepła do procesu [5]. Proces toryfikacji można podzielić na cztery etapy (rys. 2.):

1) suszenie - wydzielanie wilgoci zawartej w biomasie oraz terpenów,

2) wydzielanie $\mathrm{CO}$ i $\mathrm{CO}_{2}$, powstawanie małych ilości kwasu octowego i metanolu, początek wydzielania smoły drzewnej,

3) rozkład węglowodanów, takich jak hemiceluloza i celuloza, powstawanie węgla drzewnego oraz kwasu octowego i smoły. Wzrost temperatury do $380^{\circ} \mathrm{C}$ powoduje rozkład termiczny ligniny, wzrasta ilość wydzielającego się metanolu i smoły drzewnej. W tym czasie następuje zmniejszenie wydzielania się takich gazów, jak $\mathrm{CO}_{2}$ i $\mathrm{CO}$, a zwiększa się wydzielanie metanu i wodoru,

4) tworzenie się substancji o charakterze węglowodorowym oraz wtórne reakcje polimeryzacji i kondensacji.

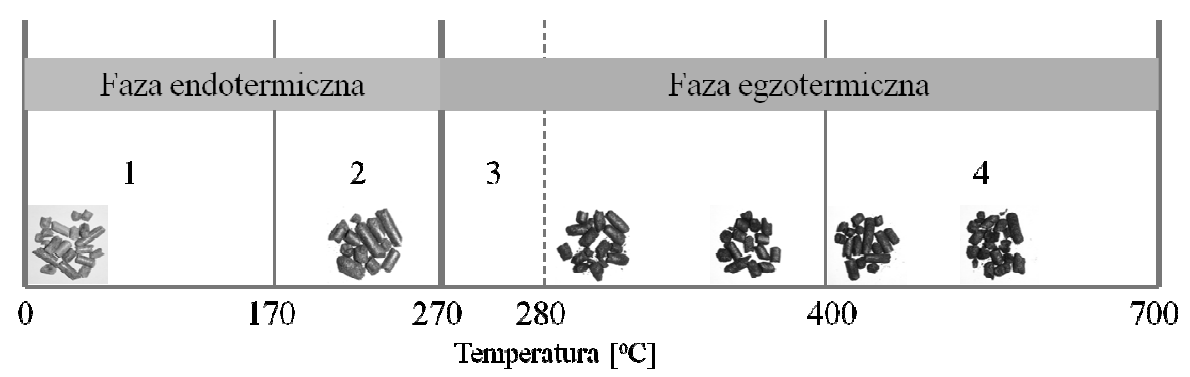

Rys. 2. Fazy procesu toryfikacji

Fig. 2. Phases of fuel torrefaction 


\section{Badania procesu toryfikacji}

Za cel prowadzonych badań obrano poznanie i analizę przebiegu procesu toryfikacji dla różnych rodzajów biomasy. Dostępna literatura nie dostarcza wystarczających informacji na ten temat. Badania procesu toryfikacji przeprowadzono dla wybranych czterech rodzajów biomasy, którymi są: zrębka, słoma, PKS (łuski palmy olejowej), śruta z oliwek. Badania przeprowadzono na stanowisku opracowanym na potrzeby realizacji procesu (rys. 3.). Stanowisko to składa się z pieca muflowego, w którego wnętrzu umieszczano reaktor wypełniony paliwem poddawanym procesowi obróbki termicznej. Piec jest wyposażony w mikroprocesorowy kontroler temperatury, pozwalający na uzyskanie i utrzymanie zadanej temperatury. Umieszczony we wnętrzu pieca reaktor był podwieszony na cięgnie wagi laboratoryjnej. Wagę połączono z układem archiwizacji danych pozwalającym na zapis zmian masy w czasie. Dodatkowo, we wnętrzu reaktora umieszczono trzy termopary umożliwiające pomiar rozkładu temperatury badanej biomasy. Równolegle z pomiarem masy próbki dokonywano rejestracji temperatury wnętrza pieca $\mathrm{TC} 0$, jak również temperatur we wnętrzu reaktora. Termopary we wnętrzu reaktora znajdowały się odpowiednio przy ściance TC1, w połowie odległości od osi reaktora TC2 i w osi reaktora TC3. Do wnętrza pieca w celu stworzenia atmosfery obojętnej podawany był gaz inertny.

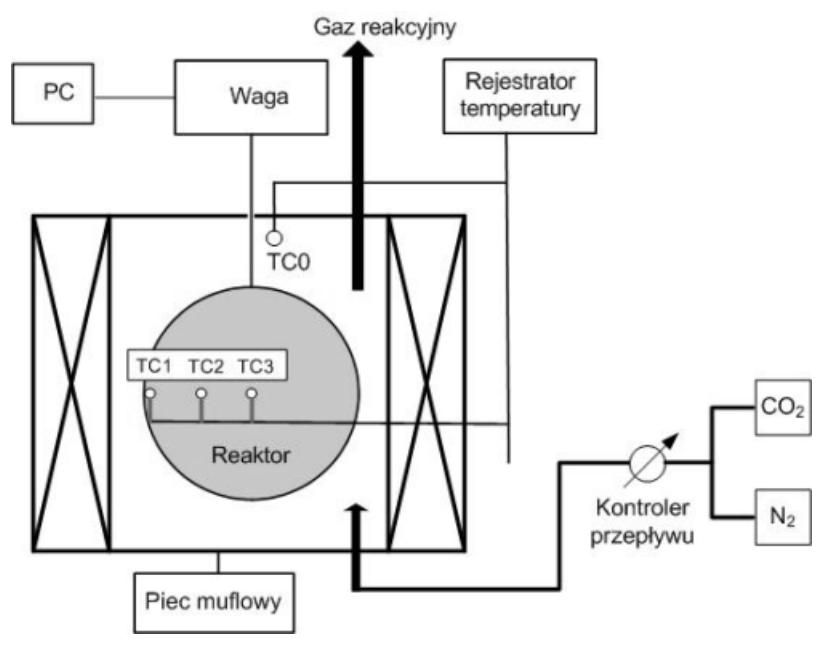

Rys. 3. Schemat stanowiska badawczego

Fig. 3. Schematic of the laboratory stand

Badania procesu toryfikacji dla wybranych rodzajów biomasy przeprowadzono dla temperatur z zakresu $250-500^{\circ} \mathrm{C}$. Czas prowadzenia procesu był uzależniony od obserwowanej zmiany masy próbki. W niniejszej pracy przedstawiono wybrane wyniki, uzyskane w temperaturze $350^{\circ} \mathrm{C}$. W tabelach 1. i 2. ze- 
stawiono wyniki dotyczące paliw w stanie surowym oraz po procesie waloryzacji w temperaturze $350^{\circ} \mathrm{C}$. Analizując dane $\mathrm{z}$ zawarte w tab. 1. i 2., można stwierdzić, że przez poddanie biomasy procesowi toryfikacji jest możliwe właściwie całkowite usunięcie wilgoci z próbki. Dodatkowo widać wyraźny spadek zawartości części lotnych w karbonizacie, przy jednoczesnym wzroście zawartości fixed carbonu (FC). Największą zawartość FC uzyskano w karbonizacie z PKS - wynosi ona ponad 66\%. Z kolei największą zawartością części lotnych po procesie charakteryzowała się zrębka (41\%). Dla wszystkich analizowanych próbek stwierdzono wzrost zawartości popiołu po waloryzacji, związany z ubytkiem masy próbki. W wyniku realizacji procesu toryfikacji uzyskano dla wszystkich badanych biomas wzrost zawartości pierwiastka $\mathrm{C}$ w karbonizacie, co się przekłada bezpośrednio na wzrost wartości ciepła spalania. Proces ten spowodował natomiast wyraźny spadek zawartości wodoru oraz tlenu w karbonizacie w porównaniu z próbkami surowymi. W przypadku azotu i siarki ich zawartość nie ulega znaczącym zmianom.

Tabela 1. Wyniki analizy technicznej paliw

Table 1. Results of proximate analysis of fuels

\begin{tabular}{|c|l|c|c|c|c|c|c|c|}
\hline \multirow{2}{*}{ Lp. } & \multirow{2}{*}{ Rodzaj biomasy } & $\mathbf{W}_{\mathbf{P}}$ & $\mathbf{W}_{\mathbf{H}}$ & $\mathbf{W}_{\mathbf{T}}$ & $\mathbf{V M}^{\mathbf{d}}$ & $\mathbf{A}_{\mathbf{5 7 5}}^{\mathbf{5}}$ & $\mathbf{F C}^{\mathbf{d}}$ \\
\cline { 3 - 8 } & \multicolumn{7}{|c|}{ \% } \\
\hline 1 & PKS surowy & 10,3 & 5,7 & 15,4 & 80,6 & 2,4 & 17,01 \\
\hline 2 & PKS $350^{\circ} \mathrm{C}$ & 0,0 & 1,8 & 1,8 & 27,9 & 5,6 & 66,50 \\
\hline 3 & Słoma surowa & 1,6 & 5,4 & 6,9 & 77,3 & 6,2 & 16,50 \\
\hline 4 & Słoma $350^{\circ} \mathrm{C}$ & 0,0 & 2,7 & 2,7 & 30,5 & 16,1 & 53,40 \\
\hline 5 & Śruta z oliwek surowa & 18,6 & 6,6 & 24,0 & 73,8 & 6,9 & 19,30 \\
\hline 6 & Śruta z oliwek $350^{\circ} \mathrm{C}$ & 0,0 & 2,0 & 2,0 & 30,6 & 17,5 & 51,90 \\
\hline 7 & Zrębka surowa & 37,2 & 4,9 & 40,3 & 81,8 & 0,5 & 17,70 \\
\hline 8 & Zrębka $350^{\circ} \mathrm{C}$ & 0,0 & 2,6 & 2,6 & 41,0 & 1,3 & 57,70 \\
\hline
\end{tabular}

Tabela 2. Wyniki analizy elementarnej paliw

Table 2. Results of ultimate analysis of fuels

\begin{tabular}{|c|l|c|c|c|c|c|c|c|}
\hline \multirow{2}{*}{ Lp. } & \multirow{2}{*}{ Rodzaj biomasy } & $\mathbf{C}^{\mathbf{d}}$ & $\mathbf{H}^{\mathbf{d}}$ & $\mathbf{N}^{\mathbf{d}}$ & $\mathbf{S}^{\mathbf{d}}$ & $\mathbf{O}^{\mathbf{d}}$ & $\mathbf{W g}^{\mathbf{d}}$ & $\mathbf{W d}^{\mathbf{d}}$ \\
\cline { 3 - 9 } & & \multicolumn{6}{|c|}{$\%$} & \multicolumn{3}{|c|}{$\mathbf{k J} / \mathbf{k g}$} \\
\hline 1 & PKS surowy & 56,00 & 6,06 & 0,09 & 0,04 & 37,81 & 19596 & 17847 \\
\hline 2 & PKS $350^{\circ} \mathrm{C}$ & 74,93 & 3,83 & 0,84 & 0,00 & 20,40 & 29255 & 28348 \\
\hline 3 & Słoma surowa & 45,57 & 5,92 & 0,16 & 0,23 & 48,12 & 17878 & 16373 \\
\hline 4 & Słoma $350^{\circ} \mathrm{C}$ & 64,07 & 3,91 & 1,26 & 0,13 & 30,63 & 24230 & 23282 \\
\hline 5 & Śruta z oliwek surowa & 49,68 & 6,29 & 0,82 & 0,28 & 42,93 & 20790 & 18775 \\
\hline 6 & Śruta z oliwek $350^{\circ} \mathrm{C}$ & 67,04 & 3,92 & 1,13 & 0,00 & 27,91 & 23157 & 22225 \\
\hline 7 & Zrębka surowa & 47,30 & 5,83 & 0,25 & 0,00 & 46,62 & 19153 & 16835 \\
\hline 8 & Zrębka $350^{\circ} \mathrm{C}$ & 74,36 & 4,81 & 0,32 & 0,02 & 20,48 & 28327 & 27179 \\
\hline
\end{tabular}


Na rysunku 4. przedstawiono przebiegi czasowe względnej zmiany masy próbki, temperatury w otoczeniu (TC0), jak i we wnętrzu reaktora (TC1, TC2, TC3) uzyskane podczas badań toryfikacji dla temperatury $350^{\circ} \mathrm{C}$. Dla wszystkich badanych biomas obserwuje się podobny przebieg zmian masy w czasie w wyniku obróbki termicznej. W początkowej fazie procesu można zauważyć pewien ubytek masy wynikający z trwającego procesu suszenia próbki. Potwierdzeniem tego są przebiegi czasowe temperatur we wnętrzu reaktora, wskazujące na trwający proces suszenia próbki $\left(100-120^{\circ} \mathrm{C}\right)$. Następnie obserwuje się szybki ubytek masy związany z intensywnym procesem wydzielania $\mathrm{CO}$ i $\mathrm{CO}_{2}$ oraz rozkładu węglowodanów, powyżej temperatury $160^{\circ} \mathrm{C}$ we wnętrzu reaktora.
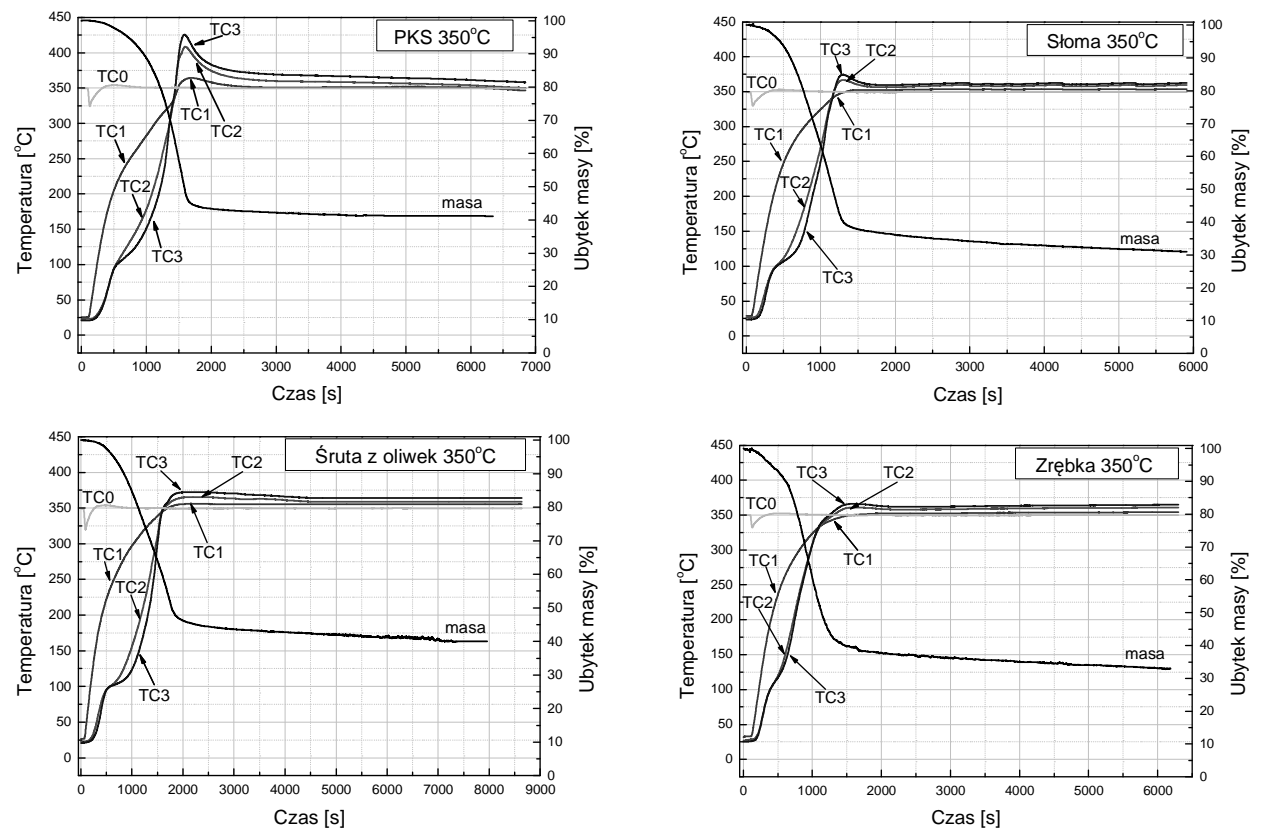

Rys. 4. Przebiegi czasowe względnej zmiany masy próbki oraz temperatury wewnątrz i w otoczeniu reaktora

Fig. 4. The waveforms of relative sample mass and temperature change inside the reactor and in reactor ambient

Po upływie około 1500-2000 s, w zależności od rodzaju badanej biomasy jest widoczne wyraźne zmniejszenie tempa ubytku masy próbki, pokrywające się czasowo z wyraźnym wzrostem temperatury. Temperatura ta przekracza poziom panujący w piecu, co świadczy o występowaniu procesu egzotermicznego we wnętrzu reaktora. Najbardziej jest to zauważalne w przypadku próbek PKS oraz słomy, natomiast mniej widoczne $\mathrm{w}$ przypadku próbek śruty $\mathrm{z}$ oliwek i zrębki. Wynika to z ubytku części lotnych, które wynoszą odpowiednio 52,7 
i 40,8\% dla próbek PKS i zrębki. Powyżej czasu 1500-2000 s nie obserwuje się już wyraźnego ubytku masy próbki, natomiast widoczny jest spadek temperatury we wnętrzu reaktora, który dąży asymptotycznie do temperatury pieca. $\mathrm{Na}$ tej podstawie można przypuszczać, że proces toryfikacji w zasadniczej części został zakończony.

a)

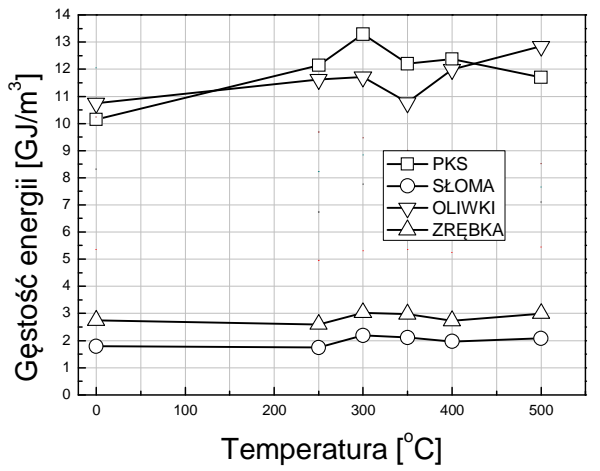

b)

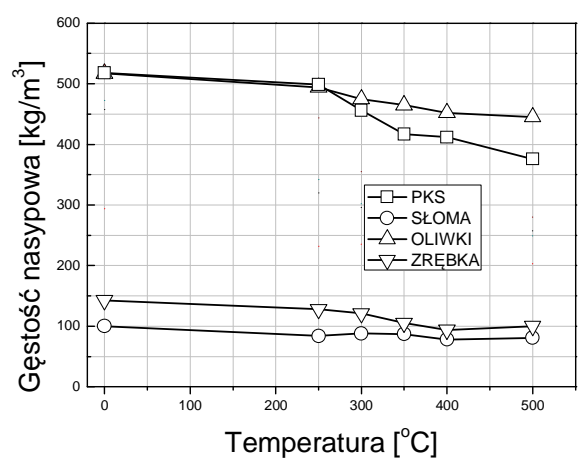

Rys. 5. Gęstość energii (a) oraz gęstość nasypowa (b) paliw w funkcji temperatury procesu Fig. 5. Energy density (a) and bulk density (b) of fuels versus process temperature

Rysunek 5. obrazuje przebieg zmian gęstości energii oraz gęstości nasypowej biomasy w zależności od temperatury procesu. Analiza wyników wskazuje, że optymalna temperatura obróbki termicznej biomasy to ok. $300^{\circ} \mathrm{C}$, gdyż odpowiadają jej najkorzystniejsze wartości gęstości energii i gęstości nasypowej.

\section{Podsumowanie}

Opierając się na informacjach zestawionych w niniejszym artykule, można stwierdzić, że obróbka termiczna (termoliza) biomasy w temperaturze $350^{\circ} \mathrm{C}$ pozwala na właściwie całkowite usunięcie wilgoci z toryfikowanej biomasy, a dodatkowo powoduje wyraźny spadek zawartości części lotnych oraz wzrost zawartości tzw. fixed carbonu w produkcie toryfikacji. W pracy wykazano także, że toryfikacja biomasy powoduje wzrost zawartości pierwiastka $\mathrm{C}$ oraz wzrost parametrów energetycznych (ciepło spalania i wartość opałowa) obrabianej termicznie biomasy.

\section{Podziękowanie}

Praca dofinansowana z BS-404-301/11. 


\section{Literatura}

[1] Karwasz Z.: Biomasa jako źródło wytwarzania energii odnawialnej w Polsce, Czysta Energia, 7-8 (2007), 16-17.

[2] Katalog firmy HERZ: Wykorzystanie biopaliw stałych w ogrzewnictwie.

[3] Lewandowski W.M.: Proekologiczne odnawialne źródła energii, wyd. IV, WNT, Warszawa 2007.

[4] Niedziółka I., Zuchniarz A.: Analiza energetyczna wybranych rodzajów biomasy pochodzenia roślinnego, http://www.pan-ol.lublin.pl/wydawnictwa/Motrol8a/Niedziolka.pdf (dostęp: 11 czerwca 2014 r.).

[5] Person K., Olofsson I., Nordin A.: Biomass Refinement by Torrefaction, Energy Technology and Thermal Process Chemistry, Umea University, Sweden 2006.

[6] Tytko R.: Odnawialne źródła energii. Wybrane zagadnienia, Wydawn. Deka, Kraków 2008.

[7] Wisz J., Matwiejew A.: Biomasa - badania w laboratorium w aspekcie przydatności do energetycznego spalania, www.systemyogrzewania.pl/ (dostęp: 8 czerwca 2011 r.).

[8] Właściwości biomasy jako paliwa, http://www.biomasa.org/index.php?d=artykul \&kat=51\&art=47 (dostęp: 1 czerwca 2014 r.).

\section{INVESTIGATION OF BIOMASS TORREFACTION PROCESS}

\section{S u m m a r y}

In this paper the changes of some chosen physico-chemical parameters of biomass as a result of its thermal treatment at the temperature of $350^{\circ} \mathrm{C}$ are investigated. The results indicate that torrefaction provides suitable conditions for complete elimination of moisture from the biomass, as well as for significant decrease of the volatile content, and the increase of the, so-called, fixed carbon. It was also demonstrated that the torrefaction of biomass brings about the increase of the carbon content in the solid product, as well as the increase of its high and low heating values and heat of combustion.

Keywords: biomass, thermal treatment, torrefaction

DOI: $10.7862 / \mathrm{rm} .2015 .12$

Otrzymano/received:14.09.2014 r.

Zaakceptowano/accepted:20.11.2014 r. 